SEÇÃO

RESENHAS 
No mistério do sem-fim equilibra-se um planeta.

E no planeta um jardim e no jardim um canteiro no canteiro uma violeta e sobre ela o dia inteiro

entre o planeta e o sem-fim a asa de uma borboleta.

Cecília Meireles 


\section{Natureza, cultura e comunidade: as potencialidades de articulação do turismo de base comunitária}

\section{Carlos Eduardo Silva}

Bartholo, R.; Sansolo, D. G.; Bursztyn, I. (orgs.). Turismo de Base Comunitária: Diversidade de Olhares e Experiências Brasileiras. Rio de Janeiro: Letra e Imagem, 2009.

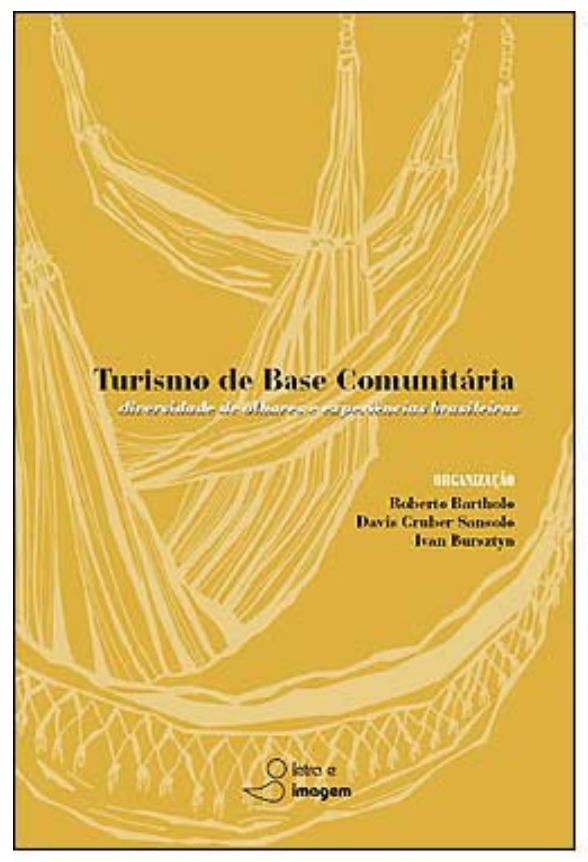

Refletindo a partir de uma visão sistêmica, na qual economia e o turismo aparecem interrelacionados e interdependentes, as comunidades não poderiam participar do processo de melhoria da sua qualidade de vida como meras expectadoras, mas sim, como agentes principais do processo de transformação dos meios de produção ultrapassados, em outros mais sustentáveis e articuladores da natureza e da cultura.

Incentivados e apoiados pelo Ministério do Turismo, através da Secretaria Nacional de Programas de Desenvolvimento do Turismo (SNPDTUR), e pela necessidade de reunir olhares e experiências sobre o turismo de base comunitária, Roberto Bartholo, Davis Gruber Sansolo e Ivan Bursztyn, pesquisadores que reúnem os ingredientes para a articulação das pessoas e dos saberes necessários para a empreitada, organizaram a obra "Turismo de Base

Comunitária: diversidade de olhares e experiências brasileiras" através da Editora Letra e Imagem.

A obra está dividida em duas partes, a primeira composta por 21 artigos, que versam sobre a diversidade de olhares para o tema da participação comunitária. A segunda parte da obra reúne um artigo e um conjunto de projetos que relatam as experiências brasileiras em turismo de base comunitária.

Após apresentação da obra, parte na qual os autores demonstram os resultados alcançados pelo Laboratório de Tecnologia e Desenvolvimento Social (LTDS) e pelo Instituto Virtual de Turismo (IVT) desde 1996, inicia-se uma viagem, a cada capítulo, pelos saberes divididos pelos artigos que se seguem.

O primeiro deles elaborado por Carlos Maldonado relata "O turismo rural comunitário na América Latina: gênesis, características e políticas" com o objetivo de desvendar as faces e explicar o surgimento do Turismo Rural Comunitário (TRC) na América Latina. 0 autor conclui que para que os povos possam ter uma vida digna se faz necessária a efetiva participação do governo no auxílio à busca do desenvolvimento dos indivíduos.

0 organizador da obra e autor do segundo artigo, Roberto Bartholo, discute "Sobre 
o sentido da proximidade: implicações para um turismo situado de base comunitária". Neste ponto percebe-se que o artigo é dotado de uma ampla e interessante revisão teórica sobre proximidade, pertencimento e as relações entre o lugar, o visitante e o popular. Hassan Zaoual nos traz sua contribuição ao escrever "Do turismo de massa ao turismo situado: quais as transições?" onde propõe um debate sobre a economia local no contexto do turismo, percebendo esse fenômeno nas transições entre concepções do turismo. Partindo do declínio do turismo de massa e chegando as diversas faces daquilo que os se convencionou chamar de "um novo turismo", que se relaciona com os conceitos de sustentabilidade.

Ivan Bursztyn, Roberto Bartholo e Mauricio Delamaro refletem sobre os beneficiários e os impactos negativos da atividade em "Turismo para quem? Sobre caminhos de desenvolvimento e alternativas para o turismo no Brasil". Os autores defendem alternativas para o turismo unicamente focado no desenvolvimento econômico, e trazem a discussão sobre o papel eminentemente importante dos atores e saberes locais em sua autotransformação. Acompanhando essa linha de raciocínio, Rita de Cássia Ariza da Cruz, traz reflexões teóricas, fundamentadas inicialmente em Trotsky, ao brindar a obra com o artigo denominado "Turismo, produção do espaço e desenvolvimento desigual: para pensar a realidade brasileira".

A pesquisadora Marta de Azevedo Irving participa da obra com "Reinventando a reflexão sobre turismo de base comunitária: inovar é possível?", onde apresenta o histórico do marginalizado conceito de turismo comunitário, e defende uma evolução inovadora e criativa no turismo, colocando as comunidades no centro do processo decisório e de ação.

Um dos organizadores da obra, Davis Gruber Sansolo, discute o "Centralismo e participação na proteção da natureza e desenvolvimento do turismo no Brasil" concluindo que se faz necessária uma ampla quebra de paradigmas no cerne da gestão e das políticas públicas relacionadas com a conservação da biodiversidade e das paisagens brasileiras, ícones necessários para o novo turismo tão desejado.

O Turismo Rural Comunitário abordado por Carlos Maldonado no início da obra volta a ser discutido em "Turismo de base comunitária: potencialidade no espaço rural brasileiro" através das percepções de Davis Gruber Sansolo e Ivan Bursztyn, com o diferencial de inserir as possibilidades de mensuração pelo uso dos indicadores aplicados à temática.

"Patrimônio cultural, turismo e identidades territoriais: um olhar geográfico" é a contribuição de Maria Tereza Duarte Paes, que apresenta a íntima relação entre o turismo e a proteção do patrimônio histórico e arquitetônico brasileiro como ícones de uma cultura admirável e atrativa.

Gustavo Vilella da Costa, Helena Catão e Rosane Prado apresentam a "Praia do Aventureiro: um caso sui generis de gestão local do turismo" objetivando apresentar o caso de turismo comunitário, percebidos nesta praia localizada em Ilha Grande, Estado do Rio de Janeiro, onde a comunidade desta praia, única na ilha, gerencia o processo comunitário de turismo. Outro caso interessante é narrado por Fernanda Carneiro e Roberto Bartholo em "Descubra a tradição de um lugar: o encontro entre nativos e biribandos em Trancoso, sul da Bahia". Neste artigo, fruto da tese de doutorado de Fernanda Carneiro é realizada 
uma reflexão sobre o encontro entre nativos e viajantes ocorrido em Trancoso (Sul da Bahia) nos anos de 1970. 0 artigo faz uma reflexão sobre a identidade e tradição do lugar.

A autora Ana Bauberger Pimentel apresenta o pensamento de Marcel Mauss sobre a dádiva e sua eminente relação com a hospitalidade na cidade do Rio de Janeiro e no Brasil ao escrever o artigo "Dádiva e hospitalidade no sistema de hospedagem domiciliar". Saindo da cidade maravilhosa, viajamos até os territórios indígenas com Rosana Eduardo da Silva Leal que apresenta "O turismo desenvolvido em territórios indígenas sob o ponto de vista antropológico" refletindo sobre a o processo de aculturação e concluindo que a etnicidade construída pelos povos indígenas contemporâneos potencializa o desenvolvimento do turismo. Outro território indígena discutido na obra é o arquipélago do Marajó, PA, que apesar de ser um ícone internacional do turismo brasileiro, apresenta alguns dos piores índices de desenvolvimento humano da região, este debate é proporcionado por Maria Goretti da Costa Tavares em "Turismo e desenvolvimento na Amazônia brasileira: algumas considerações sobre o arquipélago do Marajó (PA)". Ivani Ferreira de Faria continua o debate ampliado sobre territórios indígenas em "Ecoturismo, cultura e participação: gestão do território indígena no alto Rio Negro" apresentando tipos de impacto possíveis e diferentes formas de participação, que vão do controle do Estado ao envolvimento efetivo das comunidades.

O pensamento regionalizado deixa a Amazônia e chega ao Nordeste brasileiro com Luzia Neide Coriolano que escreve "O turismo comunitário no nordeste brasileiro". Neste artigo a autora debate a revalorização do Nordeste e as demandas por lazer, que culminaram em conflitos entre o interesse imobiliário e as possibilidades de desenvolvimento das comunidades locais. Outro caso nordestino apresentado nesta obra é o da Prainha do Canto Verde (Ceará), elaborado por Teresa Cristina de Miranda Mendonça. A autora reflete sobre a responsabilidade dos diversos públicos para com o local em "Turismo socialmente responsável da Prainha do Canto Verde: uma solução em defesa do local herdado”. Flávia Ferreira Mattos aumenta as perspectivas de debate sobre o turismo comunitário em "Ecoturismo e inclusão social na Resex Marinha do Delta do Parnaíba (MA/PI): tendências, expectativas e possibilidades" artigo no qual a autora conclui que, embora exista grande potencial para o ecoturismo nesta região, são necessárias ações mais efetivas de relacionamento das comunidades com as políticas de conservação da natureza.

"Turismo e população dos destinos turísticos: um estudo de caso do desenvolvimento e planejamento turístico na Vila de Trindade - Paraty/RJ" é apresentado por Alexandra Campos Oliveira, que discute sobre o potencial paisagístico de todas as áreas de Paraty, em especial a Vila de Trindade. A autora analisa a história e os impactos do turismo no local, destacando a participação da população nesta trajetória.

A cultura do povo quilombola é apresentada no artigo de Anelize Martins de Oliveira e Marcelo Marinho intitulado "Comunidade quilombola de Furnas do Dionísio: aspectos relacionais entre cultura, turismo e desenvolvimento local”. Neste trabalho, os autores discutem a relação entre cultura e desenvolvimento, e apresentam o valor histórico-cultural de Furnas do Dionísio, município de Jaraguari, Estado do Mato Grosso.

Enrique Sergio Blanco enfatiza a relação entre o turismo e a agricultura em "O turis- 
Natureza, cultura e comunidade: as potencialidades de articulação do turismo de base comunitária

mo rural em áreas de agricultura familiar: as 'novas ruralidades' e a sustentabilidade do desenvolvimento local". Neste artigo aborda-se o novo conceito de ruralidade, que deixa de ser apenas 'produtora de alimentos' e commodities e passa a conceber uma interrelação com outras atividades socioeconômicas. 0 trabalho traz ainda o caso das rotas turísticas do município de Dois Irmãos e região, no Rio Grande do Sul.

A segunda parte da obra é iniciada pelo artigo de Katia Silva, Rodrigo Ramiro e Breno Teixeira intitulado "Fomento do Turismo de Base Comunitária: a experiência do Ministério do Turismo". Eles abordam o histórico do Ministério do Turismo e seu crescente envolvimento ao longo da história com a concepção do turismo comunitário. Apresentando ainda os principais resultados das políticas públicas implementadas ao longo dos anos.

A segunda parte da obra é completada com a lista descritiva e individualizada dos projetos aprovados no âmbito do Edital MTur 001/2008.

Enfim, trata-se de uma obra bastante abrangente, e com potencial de multiplicação de seus conhecimentos. Traz ao leitor a teoria e a realidade, e demonstra a necessidade de ter os atores e os saberes no centro do processo, ou seja, ter efetivamente o turismo de base comunitária inserido nas políticas de desenvolvimento deste país. A obra deixou de abordar características importantes, no que diz respeito às potencialidades econômicas do artesanato e da culinária local, bem como não aprofundou uma discussão sobre a capacitação destas comunidades para uma melhor gestão do processo. No entanto, estas demandas críticas não desmerecem a contribuição da obra, que possui o mérito de reunir numa mesma edição as mais atuais experiências e saberes sobre o tema, e pode instigar novos pesquisadores a produzir mais estudos ou aprofundar os aqui apresentados.

Carlos Eduardo Silva: Instituto Socioambiental Árvore, Faculdade Ages.

Email: carlos@arvore.org.br

Link para o currículo Lattes: http://lattes.cnpq.br/3700554054159220

Data de submissão: 21 de setembro de 2009

Data de aceite: 21 de setembro de 2009 